\title{
Current Screening Methods for the Risk or Presence of Malnutrition in Cancer Patients
}

\author{
Alessio Molfino, Giovanni Imbimbo, Alessandro Laviano $\mathbb{D}$ \\ Department of Translational and Precision Medicine, Sapienza University of Rome, Rome, Italy \\ Correspondence: Alessandro Laviano, Department of Translational and Precision Medicine, Sapienza University of Rome, Viale dell'Università 37, \\ Rome, 00185, Italy, Tel/Fax +39 06 49973902, Email alessandro.laviano@uniromal.it
}

\begin{abstract}
Malnutrition is highly common among cancer patients and is associated with a poor quality of life, increased treatment toxicities and decreased survival. The screening of malnutrition should be performed in an early stage of cancer disease and should be rapid, not expensive and highly sensitive to identify the risk of developing malnutrition. Importantly, international clinical guidelines suggest to perform screening for malnutrition in all cancer patients and if the risk is present, they recommend to perform a full nutritional assessment. During the screening phase, different nutritional parameters are considered including the loss of appetite, low food intake, body weight loss and burden of the disease. These items are present in several screening tools, such as the Nutrition Risk Screening (NRS)-2002, the Malnutrition Universal Screening Tool (MUST) and the Mini Nutritional Assessment (MNA) which represent the most widely used tools to screen for an altered nutritional status in cancer patients. Recently, the Global Leadership Initiative on Malnutrition (GLIM) developed an assessment tool for the diagnosis of malnutrition taking into account the presence of i) involuntary body weight loss, ii) body mass index, iii) low muscle mass, iv) low food intake and disease burden/inflammation; in particular, body weight loss, decreased body mass index (BMI), and low muscle mass are considered as phenotypic criteria, whereas reduced food intake, disease burden and inflammation are defined as etiologic criteria. To perform the diagnosis of malnutrition, GLIM consensus considered the presence of at least one phenotypic and one etiologic criterion. The above-mentioned screening tools were validated in different clinical settings and suggesting the use of one tool vs another is challenging considering, among others, different factors including the type and stage of cancer and the setting (i.e., inpatient or outpatient care). Recent data obtained among large cohorts of cancer patients indicate that personalized nutritional therapy reduced mortality risk and ameliorated quality of life and functionality among cancer patients with high nutritional risk, supporting the urgent need for implementing screening and diagnosis of malnutrition in this context.
\end{abstract}

Keywords: malnutrition, cancer, cachexia, screening, assessment, body weight loss, anorexia

\section{Introduction}

Cancer was estimated to account for more than 10 million deaths in 2020 with an expected increase of new cancer cases per year of 29.5 million in 2040 worldwide. ${ }^{1}$ Malnutrition is common among cancer patients and was estimated to range from $50-80 \%$ in advanced malignant cancer and to account for $20 \%$ of cancer deaths. ${ }^{2}$ Malnutrition in cancer was also associated with a poor quality of life, increased treatment toxicities and poor outcomes. ${ }^{3}$ Importantly, the prevalence of malnutrition in patients with cancer varies according to tumor type and stage. ${ }^{4}$ Pancreatic, gastro-esophageal, lung and head and neck are considered the type of cancers most associated with malnutrition differently from prostate and breast cancer which are less related to poor nutritional status. ${ }^{3}$

Malnutrition or undernutrition was defined by the European Society of Clinical Nutrition as

a state resulting from lack of intake or uptake of nutrition that leads to altered body composition (decreased fat free mass) and body cell mass leading to diminished physical and mental function and impaired clinical outcome from disease. ${ }^{5}$

The ESPEN guidelines on definitions and terminology of clinical nutrition recognized three types of malnutrition: disease-related malnutrition (DRM) with inflammation, DRM without inflammation and malnutrition/undernutrition without disease. ${ }^{5}$ Moreover, DRM with inflammation may be associated either with chronic diseases such as cancer 
and chronic kidney diseases or with acute illness such as sepsis or acute injuries. ${ }^{5}$ Chronic DRM with inflammation was considered a synonym of cachexia. In this light, for correct and early identification of malnutrition in a clinical setting it is necessary to consider patient's comorbidities and in turn to apply the validated screening and/or assessment tools.

In the present article, we aimed to describe the most widely used screening tools for malnutrition in cancer patients and to analyze the international guidelines regarding which tool(s) is more appropriate according to the specific clinical settings (e.g., in-hospital, outpatient, community). In addition, we focused on the differences and analogies of the available screening instruments in terms of items included or not in each tool. Moreover, we described the new Global Leadership Initiative on Malnutrition (GLIM) criteria as a potential novel reliable tool for the diagnosis of malnutrition in cancer.

\section{Malnutrition Screening Tools}

The screening of malnutrition is a process intended to identify early the risk for developing malnutrition. To improve the efficacy of nutritional screening, it has to be rapid, not expensive and with high sensitivity. ${ }^{6}$ Importantly, clinical guidelines suggest performing nutritional screening in all cancer patients and, if the risk of malnutrition is present, they recommend completing a full nutritional assessment. ${ }^{6}$ The risk of malnutrition, even without presence of malnutrition, was associated with worse clinical outcomes. ${ }^{7}$ In a validation study, the risk of malnutrition assessed by PatientGenerated Subjective Global Assessment Short Form (PG-SGA SF) was associated with increased mortality. ${ }^{8}$ The PGSGA SF is a validated screening tool used in different clinical settings, including inpatients and outpatients ${ }^{9}$ (Table 1). It can be easily completed by the patient as nutritional screening, and by healthcare professionals as a screening, assessment or monitoring instrument. ${ }^{9}$ In addition, a global assessment of malnutrition may be performed by the full form of PGSGA which includes a second section addressing more specific information on nutritional status, including parameters of metabolic demand, physical exam and disease and its relation to nutritional requirements. ${ }^{9}$

Several screening assessment tools have been described to identify the risk of malnutrition in different settings and we have indicated the items included in each tool in Table 1.

In particular, these tools consider the etiologies (e.g., inflammation, disease associated with malnutrition), symptoms (e.g., anorexia) and signs (e.g., weight loss) of malnutrition to assess the grade of risk for developing poor nutritional status. Importantly, cancer patients presented specific pathophysiological and clinical aspects with high risk of malnutrition. ${ }^{10}$ All these aspects have to be considered in a cancer patient evaluation to detect malnutrition early and improve metabolic and nutritional status.

\section{Early Detection of Malnutrition in Cancer Patients}

For early detection of nutritional derangements in cancer patients, clinical guidelines suggest to assess changes in body weight over time (generally in the prior 3-6 months), body mass index (BMI), food intake and anorexia. ${ }^{6,11,12}$

These parameters are generally included in most of the tools available and give important information on the nutritional status of cancer patients.

The use of a specific complete screening tool may be useful in order to collect data obtaining a quantitative score of the nutritional status and to follow-up patients systematically. After screening, if a patient is at risk of malnutrition, a complete assessment of malnutrition should be completed in order to schedule an early nutritional intervention.

\section{Body Weight Loss and BMI}

Due to several metabolic alterations, patients with cancer present with an increased energy expenditure and a decreased energy intake which, in turn, determines an altered energy balance. ${ }^{3,13-15}$ In cancer patients body weight loss and decreased BMI are proxy of the wasting process which involves particularly the peripheral tissues (muscle mass and adipose tissue). ${ }^{16}$

In this light, the most widespread cancer cachexia definitions take into consideration the potential changes occurring in muscle and adipose compartments. To estimate the effect of alterations in body weight loss and in BMI on cancer patients' prognosis, Martin et al. developed a grading system by collecting data from 8675 patients with different types of cancer. ${ }^{16}$ According to this model, a cancer patient with a body weight loss of $5 \%$ and a BMI of $24 \mathrm{~kg} / \mathrm{m}^{2}$ presents with 
Table I Characteristics of the MUST, NRS-2002, MNA-SF and PG-SGA SF Tools

\begin{tabular}{|c|c|c|c|c|}
\hline & MUST $^{22}$ & NRS-2002 ${ }^{10}$ & MNA-SF ${ }^{30}$ & PG-SGA SF 9 \\
\hline Settings & Multiple & In-Hospital & Geriatric & Multiple \\
\hline Scoring system & $\begin{array}{l}\text { Score } 0=\text { low risk Score } 1= \\
\text { medium risk Score } 2=\text { high risk }\end{array}$ & Not present & $\begin{array}{l}12-14 \text { points: normal } \\
\text { 8-II points: at risk } \\
0-7 \text { points: malnourished }\end{array}$ & $\begin{array}{l}\text { 0-36 points (higher score indicates } \\
\text { poorer nutritional status) }\end{array}$ \\
\hline BMI assessment & $\begin{array}{l}>20=0 \\
18.5-20=1 \\
<18.5=2\end{array}$ & $\begin{array}{l}\text { At risk if BMl } \\
<20.5 \mathrm{~kg} / \mathrm{m}^{2}\end{array}$ & $\begin{array}{l}0=\text { BMI less than } 19 \\
1=\text { BMI } 19 \text { to less than } 21 \\
2=\text { BMI } 21 \text { to less than } 23 \\
3=\text { BMI } 23 \text { or greater }\end{array}$ & Not present \\
\hline $\begin{array}{l}\text { Body weight loss in } \\
\text { previous } 3 / 6 \text { months }\end{array}$ & $\begin{array}{l}<5 \%=0 \\
5-10 \%=1 \\
>10 \%=2\end{array}$ & Yes, or not & $\begin{array}{l}>3 \mathrm{~kg}=0 \\
\mathrm{I}=\text { does not know } \\
2=\text { weight loss between I } \\
\text { and } 3 \mathrm{~kg}(2.2 \text { and } 6.6 \mathrm{lbs}) \\
3=\text { no weight loss }\end{array}$ & $\begin{array}{l}\text { During the last } 2 \text { weeks: } \\
I=\text { decreased } \\
0=\text { not changed or increased }\end{array}$ \\
\hline Food intake & $\begin{array}{l}\text { If patient is acutely ill and there } \\
\text { has been or is likely to be no } \\
\text { nutritional intake for }>5 \text { days }\end{array}$ & $\begin{array}{l}\text { Reduced } \\
\text { dietary intake } \\
\text { in the last } \\
\text { week }\end{array}$ & $\begin{array}{l}\text { In previous } 3 \text { months } \\
\text { Severe }=0 \\
\text { Moderate }=1 \\
\text { No decrease }=2\end{array}$ & $\begin{array}{l}\text { Food intake during the past month } \\
0=\text { unchanged or increased } \\
\mathrm{I}=\text { less than usual } \\
+ \text { evaluation of type of food intake } \\
\text { changes } \\
+ \text { evaluation of different symptoms } \\
\text { including those related to anorexia } \\
\text { (e.g., appetite, nausea etc.) }\end{array}$ \\
\hline Burden of disease & & $\begin{array}{l}\text { Admission in } \\
\text { ICU }\end{array}$ & $\begin{array}{l}\text { Including presence of } \\
\text { psychological stress or acute } \\
\text { disease in the past } 3 \text { months } \\
0=\text { yes; } 2 \text { = no }\end{array}$ & Not evaluated \\
\hline Mobility & Not evaluated & $\begin{array}{l}\text { Not } \\
\text { evaluated }\end{array}$ & $\begin{array}{l}0=\text { bed or chair bound } \\
1=\text { able to get out of bed } / \\
\text { chair but does not go out } \\
2=\text { goes out }\end{array}$ & $\begin{array}{l}\text { Functional activity self-evaluated } \\
\text { over the past month }\end{array}$ \\
\hline $\begin{array}{l}\text { Neuropsychological } \\
\text { problems }\end{array}$ & Not evaluated & $\begin{array}{l}\text { Not } \\
\text { evaluated }\end{array}$ & $\begin{array}{l}0=\text { severe dementia or } \\
\text { depression } \\
1=\text { mild dementia } \\
2=\text { no psychological } \\
\text { problems }\end{array}$ & Not evaluated \\
\hline $\begin{array}{l}\text { Full nutritional } \\
\text { assessment }\end{array}$ & If score $\geq$ I & $\begin{array}{l}\text { If "Yes" to } \\
\text { any }\end{array}$ & If score is 11 or less & Not specified \\
\hline $\begin{array}{l}\text { Time required to } \\
\text { complete the } \\
\text { questionnaire }\end{array}$ & $\sim 1 \min$ & $\sim 1 \min$ & $\sim 2 \min$ & $\sim 5 \min$ \\
\hline
\end{tabular}

Abbreviations: BMI, body mass index; MUST, Malnutrition Universal Screening Tool; NRS-2002, Nutrition Risk Screening 2002; MNA-SF, Mini Nutritional AssessmentShort Form; PG-SGA-SF, Patient-Generated Subjective Global Assessment-Short Form.

an estimated median survival of 10.8 months. ${ }^{16}$ Based on these observations, the presence of involuntary body weight loss represents a "red flag" to urgently perform an accurate evaluation of the nutritional status in cancer.

Importantly, in cancer patients a body weight loss $>5 \%$ is considered predictive of poor clinical outcomes with the risk increasing consistently with higher grade of body weight loss. ${ }^{16}$ 


\section{Anorexia and Low Food Intake}

Loss of appetite, i.e. anorexia, and low food intake are important predictors of body weight loss and mortality in patients with chronic diseases and particularly in those with cancer. ${ }^{17-19}$ Anorexia and low food intake are highly prevalent in cancer patients and occur early during the cancer progression. ${ }^{17}$ In a large multinational survey including cancer patients, anorexia was the main cause for reduced food intake, which in turn was a strong predictor of 30-day mortality. ${ }^{18}$ Moreover, low food intake in the previous 7 days and involuntary weight loss in the previous 3 months were similar predictors of mortality. ${ }^{18}$ In hospitalized medical patients, anorexia assessed by different assessment tools was shown to correlate with nutritional derangements. ${ }^{20}$ Recently, the performance of different appetite assessment tools was evaluated taking into consideration the percentage of food intake and body weight loss in a large cohort of different cancer patients at their first oncology visit. ${ }^{19}$ In this study, the appetite tools performed well when low food intake (i.e., $<50 \%$ ) was used as criterion measure. ${ }^{19}$ However, suggesting the use of a specific tool is challenging, in particular due to the several domains of anorexia that may not be completely investigated by a single appetite instrument/questionnaire. ${ }^{19}$ In particular, the Functional Assessment of Anorexia/Cachexia Therapy (FAACT) score explores several domains (by 12 questions) and for this reason may be considered more comprehensive and likely accurate. However, data showed that the FAACT score and the self-assessment of appetite were strongly associated with low food intake and, importantly, anorexia was prospectively associated with body weight loss over time. ${ }^{19}$

Different screening assessment tools do not assess the presence/absence of anorexia but only evaluate food intake. Although anorexia and low food intake (hypophagia) are closely related, these two clinical parameters should both be considered as important nutritional information. In fact, patients with cancer may present with anorexia but with still preserved energy and protein intake due to the administration of artificial nutrition. In addition, Abraham et al. showed that anorexia, as assessed by FAACT score, predicted survival better compared with BMI and body weight loss in esophagogastric cancer patients. ${ }^{17}$

In this light, considering anorexia as an early event during cancer progression its evaluation may be useful in the screening process to early tackle nutritional derangements.

Food intake may be assessed by questionnaires or by analyzing patient food records. ${ }^{5}$ Assessment via validated questionnaires may be useful for screening purpose. Asking patients to report actual food intake compared with their most recent meal with the usual food intake was shown to be reliable in different settings for the assessment of low food

intake. ${ }^{18,19,21}$ Food diaries allow us to measure the intakes quantitatively and qualitatively in terms of protein and energy intake. However, this methodology presents several limitations for screening purpose, including longer time to complete the diaries and the need of a trained dietitian. For these reasons, these instruments are often used for the assessment of malnutrition rather than for screening purposes.

\section{Malnutrition Universal Screening Tool (MUST)}

The MUST is one of the widely used screening tools and is based on the evaluation of BMI, involuntary weight loss (\%) in the previous 3-6 months and on the burden of acute illnesses (Table 1). ${ }^{22,23}$ The score ranges from 0 to 6 , with $0=$ low risk, $1=$ medium risk and $\geq 2$ high risk. ${ }^{22}$ MUST was initially designed for community settings, however, this tool was used in several other clinical settings, such as the intensive care unit, patients with chronic diseases and cancer. ${ }^{24}$ In cancer patients, MUST score was associated with worse clinical outcomes. ${ }^{22}$ In particular, Almasaudi et al. showed that in patients undergoing surgery for colorectal cancer, MUST score was associated with alterations in adiposity and muscularity and, importantly, it was independently associated with the length of stay and with decreased survival. ${ }^{22}$ The cornerstones of MUST are the evaluation of BMI and involuntary body weight loss. Within the MUST, the evaluation of appetite and food intake is limited. In fact, the only item of MUST is represented by the presence of no nutritional intake for $>5$ days. We believe that although some of the parameters can be self-reported by the patients, it is advisable for the MUST to be completed by healthcare professionals.

\section{Nutrition Risk Screening (NRS)-2002}

The NRS-2002 was developed specifically to detect the risk of malnutrition in hospitalized patients. ${ }^{10}$ It includes an initial and a final screening phase. The first phase is composed of 4 questions that, as well as for the MUST, evaluates the BMI, body weight loss and the reduction of food intake but it assesses also the status of critically or non-critically ill 
patients (Table 1). The final phase of screening has to be completed if the answer is "yes" to at least one question of the initial screening. It consists of the evaluation of impairment of nutritional status with a more detailed assessment of BMI, weight loss and food intake, and the evaluation of the severity of the disease.

Considering the medical information needed to complete the NRS-2002, the direct involvement of trained healthcare professionals is recommended.

In a secondary analysis of the overall Effect of early nutritional support on Frailty, Functional Outcomes, and Recovery of malnourished medical inpatients Trial (EFFORT) study, ${ }^{25}$ which included 2028 inpatients with a NRS score $\geq 3$, a significant increased risk of 30-day mortality (adjusted hazard ratio 1.22) and 180-day mortality (adjusted hazard ratio 1.37) were observed. ${ }^{26}$ A higher NRS score was associated with an increased length of stay and an increased impairment of activities of daily living and quality of life. ${ }^{26}$ These data were also confirmed in cancer patients, where those participants identified as at risk of malnutrition by NRS-2002 score presented with a decreased overall survival and worse clinical outcomes. ${ }^{7,27}$ Moreover, another secondary analysis of the EFFORT study ${ }^{25}$ showed that in hospitalized cancer patients at high risk of malnutrition, personalized nutritional intervention resulted in increased survival and better quality of life. ${ }^{28}$ Also, Bargetzi et al. observed that inflammation may affect the efficacy of nutritional intervention; ${ }^{29}$ in particular, patients with low C-reactive protein (CRP) showed an increased survival after nutritional intervention with respect to patients with high $\mathrm{CRP}{ }^{29}$

\section{Mini Nutritional Assessment-Short Form (MNA-SF)}

The MNA was specifically designed to address the risk of malnutrition in older adults. ${ }^{30}$ This tool, in addition to the evaluation of BMI, weight loss, decreased food intake, burden of disease, investigates the presence of neuropsychological problems (dementia or depression) and low mobility that are common in a geriatric setting. If the patient is identified as being at risk of malnutrition or malnourished, a more comprehensive evaluation should be performed to evaluate the possible underlying causes of the nutritional derangements. Considering the information needed to complete the form, the involvement of a trained healthcare professional is recommended. In cancer patients, the risk of malnutrition was present in 51\% according to MNA scoring with the highest prevalence in patients with gastroesophageal, pancreatic, head and neck, and lung cancer. ${ }^{31}$ A recent systematic review analyzed the association of MNA score with different outcomes, showing that malnourished patients presented a decreased survival and reduced quality of life. ${ }^{32}$

\section{The Global Leadership Initiative on Malnutrition (GLIM) Criteria}

After the screening of malnutrition, if a patient is considered at risk, a more comprehensive clinical evaluation should follow. In 2016, the GLIM developed an assessment tool for the diagnosis of malnutrition taking into consideration five items selected by the GLIM working group (involuntary body weight loss; body mass index (BMI); low muscle mass; low food intake; disease burden/inflammation). ${ }^{33}$ Body weight loss, decreased BMI, and low muscle mass were considered as phenotypic criteria, whereas reduced food intake and disease burden and inflammation were defined as etiologic criteria. To diagnose malnutrition GLIM consensus considered the presence of at least one phenotypic and one etiologic criterion.

GLIM criteria were validated in several settings. ${ }^{34,35}$ In older adult cancer patients, the diagnosis of malnutrition performed by using GLIM criteria was associated with decreased survival. ${ }^{7}$ This tool is easy to apply and has allowed a standardization among the several definitions and criteria for the diagnosis of malnutrition. ${ }^{33}$

According to the ESPEN endorsed recommendations, the GLIM initiative aims at adopting internationally recognized criteria so that malnutrition prevalence, therapies, and outcomes might be compared across different countries. ${ }^{33}$

This will allow the implementation of standards of care in order to ameliorate the outcomes of malnourished patients.

In this light, we believe that this innovative strategy can be fully adopted in the oncology setting where a prompt and accurate diagnosis and early therapeutic intervention are needed to improve a patient's prognosis.

\section{Conclusions}

Malnutrition is a negative prognostic factor in cancer patients. Different methodologies and tools are available to assess the risk of malnutrition in cancer patients in order to identify and treat this condition early. Different screening tools were 
validated in different settings and suggesting the use of one tool vs another appears challenging, taking into account that each patient may present important peculiarities due to several factors, including the type and stage of cancer disease and the setting (i.e., inpatient or outpatient care).

The majority of the screening tools include information on involuntary body weight loss, food intake and BMI. However, some information is specific to a single tool (e.g. MNA), including evaluation of mobility and cognitive decline. In this light, MNA is well implemented in the geriatric population whereas the other tools have been used in different clinical settings, including in-hospital patients (with different acute or chronic conditions) and community individuals. Considering the negative effects of malnutrition, the ESPEN recommends to perform nutritional screening as soon as possible, especially during catabolic conditions, such as cancer. Nutritional screening tools should be simple to use, affordable and highly sensitive.

For this purpose, BMI, involuntary body weight loss and food intake are common indicators in many screening tools, such as NRS-2002, MUST and MNA-SF. Nutritional screening cannot provide adequate information to guide treatment. If a patient is at risk of malnutrition after screening, completion of a complementary nutritional assessment is required.

Taking into account the important results obtained among large cohorts of cancer patients highlighting that personalized nutritional therapy reduced mortality risk and ameliorated quality of life and functionality among cancer patients with high nutritional risk, we identify that there is an urgent need for the implementation of screening and diagnosis programs of malnutrition in this setting.

\section{Disclosure}

Professor Alessandro Laviano reports personal fees from Abbott, BBraun, Fresenius Kabi, Nestlé Health Scence, Nutricia, and Baxter, outside the submitted work. The authors report no other conflicts of interest in this work.

\section{References}

1. World Health Organization. Cancer fact sheets. Available from: https://gco.iarc.fr/today/fact-sheets-cancers. Accessed January $26,2022$.

2. Argilés JM, Busquets S, Stemmler B, López-Soriano FJ. Cancer cachexia: understanding the molecular basis. Nat Rev Cancer. 2014;14(11):754762. doi:10.1038/nrc3829

3. Baracos VE, Martin L, Korc M, Guttridge DC, Fearon KCH. Cancer-associated cachexia. Nat Rev Dis Primers. 2018;4:17105. doi:10.1038/ nrdp. 2017.105

4. Hébuterne X, Lemarié E, Michallet M, de Montreuil CB, Schneider SM, Goldwasser F. Prevalence of malnutrition and current use of nutrition support in patients with cancer. J Parenter Enteral Nutr. 2014;38(2):196-204. doi:10.1177/0148607113502674

5. Cederholm T, Barazzoni R, Austin P, et al. ESPEN guidelines on definitions and terminology of clinical nutrition. Clin Nutr. 2017;36(1):49-64. doi:10.1016/j.clnu.2016.09.004

6. Arends J, Bachmann P, Baracos V, et al. ESPEN guidelines on nutrition in cancer patients. Clin Nutr. 2017;36(1):11-48. doi:10.1016/j. clnu.2016.07.015

7. Zhang X, Tang M, Zhang Q, et al. The GLIM criteria as an effective tool for nutrition assessment and survival prediction in older adult cancer patients. Clin Nutr. 2021;40(3):1224-1232. doi:10.1016/j.clnu.2020.08.004

8. De Groot LM, Lee G, Ackerie A, van der Meij BS. Malnutrition screening and assessment in the cancer care ambulatory setting: mortality predictability and validity of the patient-generated subjective global assessment short Form (PG-SGA SF) and the GLIM criteria. Nutrients. 2020;12(8):2287. doi:10.3390/nu12082287

9. Jager-Wittenaar H, Ottery FD. Assessing nutritional status in cancer: role of the patient-generated subjective global assessment. Curr Opin Clin Nutr Metab Care. 2017;20(5):322-329. doi:10.1097/MCO.0000000000000389

10. Kondrup J, Allison SP, Elia M, Vellas B, Plauth M. Educational and clinical practice committee, European Society of Parenteral and Enteral Nutrition (ESPEN). ESPEN guidelines for nutrition screening 2002. Clin Nutr. 2003;22(4):415-421.

11. Aapro M, Arends J, Bozzetti F, et al. Early recognition of malnutrition and cachexia in the cancer patient: a position paper of a European School of Oncology Task Force. Ann Oncol. 2014;25(8):1492-1499. doi:10.1093/annonc/mdu085

12. Arends J, Strasser F, Gonella S, et al. Cancer cachexia in adult patients: ESMO Clinical Practice Guidelines ž ESMO Open. $2021 ; 6(3): 100092$. doi:10.1016/j.esmoop.2021.100092

13. Peixoto da Silva S, Santos JMO, Costa E, Silva MP, Gil da costa RM. Cancer cachexia and its pathophysiology: links with sarcopenia, anorexia and asthenia. J Cachexia Sarcopenia Muscle. 2020;11(3):619-635. doi:10.1002/jcsm.12528

14. Molfino A, Laviano A, Rossi Fanelli F. Contribution of anorexia to tissue wasting in cachexia. Curr Opin Support Palliat Care. 2010;4(4):249-253. doi:10.1097/SPC.0b013e32833e4aa5

15. Molfino A, Iannace A, Colaiacomo MC, et al. Cancer anorexia: hypothalamic activity and its association with inflammation and appetite-regulating peptides in lung cancer. J Cachexia Sarcopenia Muscle. 2017;8(1):40-47. doi:10.1002/jcsm.12156

16. Martin L, Senesse P, Gioulbasanis I, et al. Diagnostic criteria for the classification of cancer-associated weight loss. J Clin Oncol. 2015;33(1):9099. doi:10.1200/JCO.2014.56.1894

17. Abraham M, Kordatou Z, Barriuso J, et al. Early recognition of anorexia through patient-generated assessment predicts survival in patients with oesophagogastric cancer. PLoS One. 2019;14(11):e0224540. doi:10.1371/journal.pone.0224540 
18. Hiesmayr M, Schindler K, Pernicka E, et al. Decreased food intake is a risk factor for mortality in hospitalised patients: the nutritionday survey 2006. Clin Nutr. 2009;28(5):484-491. doi:10.1016/j.clnu.2009.05.013

19. Molfino A, de van der Schueren MAE, Sánchez-Lara K, et al. Cancer-associated anorexia: validity and performance overtime of different appetite tools among patients at their first cancer diagnosis. Clin Nutr. 2021;40(6):4037-4042. doi:10.1016/j.clnu.2021.02.016

20. Arezzo Di Trifiletti A, Misino P, Giannantoni P, et al. Comparison of the performance of four different tools in diagnosing disease-associated anorexia and their relationship with nutritional, functional and clinical outcome measures in hospitalized patients. Clin Nutr. 2013 ;32(4):527-532. doi:10.1016/j.clnu.2012.11.011

21. Molfino A, Kaysen GA, Chertow GM, et al. Validating appetite assessment tools among patients receiving hemodialysis. $J$ Ren Nutr. 2016;26 (2):103-110. doi:10.1053/j.jrn.2015.09.002

22. Almasaudi AS, McSorley ST, Dolan RD, et al. The relation between Malnutrition Universal Screening Tool (MUST), computed tomographyderived body composition, systemic inflammation, and clinical outcomes in patients undergoing surgery for colorectal cancer. Am $J$ Clin Nutr. 2019;110(6):1327-1334. doi:10.1093/ajen/nqz230

23. Boléo-Tomé C, Monteiro-Grillo I, Camilo M, Ravasco P. Validation of the Malnutrition Universal Screening Tool (MUST) in cancer. Br J Nutr. 2012;108(2):343-348. doi:10.1017/S000711451100571X

24. van Bokhorst-de van der Schueren MA, Guaitoli PR, Jansma EP, de Vet HC. Nutrition screening tools: does one size fit all? A systematic review of screening tools for the hospital setting. Clin Nutr. 2014;33(1):39-58. doi:10.1016/j.clnu.2013.04.008

25. Schuetz P, Fehr R, Baechli V, et al. Individualised nutritional support in medical inpatients at nutritional risk: a randomised clinical trial. Lancet. 2019;393(10188):2312-2321. doi:10.1016/S0140-6736(18)32776-4

26. Hersberger L, Bargetzi L, Bargetzi A, et al. Nutritional risk screening (NRS 2002) is a strong and modifiable predictor risk score for short-term and long-term clinical outcomes: secondary analysis of a prospective randomised trial. Clin Nutr. 2020;39(9):2720-2729. doi:10.1016/j. clnu.2019.11.041

27. Hsueh SW, Lai CC, Hung CY, et al. A comparison of the MNA-SF, MUST, and NRS-2002 nutritional tools in predicting treatment incompletion of concurrent chemoradiotherapy in patients with head and neck cancer. Support Care Cancer. 2021;29(9):5455-5462. doi:10.1007/s00520-02106140-w

28. Bargetzi L, Brack C, Herrmann J, et al. Nutritional support during the hospital stay reduces mortality in patients with different types of cancers: secondary analysis of a prospective randomized trial. Ann Oncol. 2021;32(8):1025-1033. doi:10.1016/j.annonc.2021.05.793

29. Bargetzi L, Bargetzi M, Laviano A, Stanga Z, Schuetz P. Inflammation reduces the effect of nutritional therapy on clinical outcomes in cancer patients. Ann Oncol. 2021;32(11):1451-1452. doi:10.1016/j.annonc.2021.08.1989

30. Wildiers $\mathrm{H}$, Heeren P, Puts M, et al. International society of geriatric oncology consensus on geriatric assessment in older patients with cancer. $J$ Clin Oncol. 2014;32(24):2595-2603. doi:10.1200/JCO.2013.54.8347

31. Muscaritoli M, Lucia S, Farcomeni A, et al. Prevalence of malnutrition in patients at first medical oncology visit: the PreMiO study. Oncotarget. 2017;8(45):79884-79896. doi:10.18632/oncotarget.20168

32. Torbahn G, Strauss T, Sieber CC, Kiesswetter E, Volkert D. Nutritional status according to the mini nutritional assessment (MNA) ${ }^{\circledR}$ as potential prognostic factor for health and treatment outcomes in patients with cancer - a systematic review. BMC Cancer. 2020;20(1):594. doi:10.1186/ s12885-020-07052-4

33. Cederholm T, Jensen GL, Correia MITD, et al. GLIM criteria for the diagnosis of malnutrition - A consensus report from the global clinical nutrition community. Clin Nutr. 2019;38(1):1-9. doi:10.1016/j.clnu.2018.08.002

34. Ballesteros-Pomar MD, Gajete-Martín LM, Pintor-de-la-maza B, et al. Disease-related malnutrition and sarcopenia predict worse outcome in medical inpatients: a cohort study. Nutrients. 2021;13(9):2937. doi:10.3390/nu13092937

35. Rosnes KS, Henriksen C, Høidalen A, Paur I. Agreement between the GLIM criteria and PG-SGA in a mixed patient population at a nutrition outpatient clinic. Clin Nutr. 2021;40(8):5030-5037. doi:10.1016/j.clnu.2021.07.019

Cancer Management and Research

Dovepress

Publish your work in this journal

Cancer Management and Research is an international, peer-reviewed open access journal focusing on cancer research and the optimal use of preventative and integrated treatment interventions to achieve improved outcomes, enhanced survival and quality of life for the cancer patient. The manuscript management system is completely online and includes a very quick and fair peer-review system, which is all easy to use. Visit http://www.dovepress.com/testimonials.php to read real quotes from published authors.

Submit your manuscript here: https://www.dovepress.com/cancer-management-and-research-journal 